\title{
Analysis of the efficiency of financial support for agriculture in China under
}

\section{the DEA model}

\author{
Li Qiu \\ Shenyang Agricultural University, \\ Shenyang, Liaoning, 110866 \\ Liaoning Shihua university \\ Fushun, Liaoning, 113001
}

\author{
Wang Chun-ping \\ Shenyang Agricultural University, \\ Shenyang, Liaoning, 110866 \\ ${ }^{*}$ Corresponding author
}

\begin{abstract}
The development and growth of modern agriculture can not be separated from the government, policy support, especially financial support. There is a huge contradiction between limited financial resources and agricultural expenditure, if agricultural production relies on the expansion of the scale of fiscal expenditure, it is not a permanent solution. Therefore, it is very important to improve the efficiency of financial expenditure on agriculture, which is an important way to promote the rapid development of agricultural economy and ease the contradiction between supply and demand of rural finance.
\end{abstract}

Keywords-DEA model, China, Financial support for agriculture, Fund efficiency, Evaluation.

\section{INTRODUCTION}

As the restriction of longer cycle of agricultural production, the capital turnover is slow, the benefit is not only affected by natural conditions, but also by the market price fluctuation. Therefore, compared with other industries, agricultural risk and anti- risk ability are weak. Our country is a large agricultural country, the agricultural development of China's economic construction has important influence. Although in all aspects, China's agricultural output has great improvement, but because of the infrastructure, public utilities and other development is slow, it is difficult to support modern agricultural development needs, which makes the farmers' income increase slowly and the agricultural industry system, production management become a big problem. The solution of these problems requires the government to strengthen the intervention and maintenance of agriculture, through financial support and promote the stable growth of the rural economy.

\section{DEA model analysis}

DEA, also known as data envelopment analysis (Envel Analysis Data), proposed by Charnes Cooper, Rhodes in 1978, is a relative efficiency evaluation of the non- parametric programming method.

Since 2007, China's fiscal expenditure statistics occurred huge change, for financial support to the investment amount was not disclosure in public, so scale efficiency and use efficiency, generally used total fiscal expenditure of province as input indicators, and showed as expenditure of fiscal expenditure in agriculture, forestry, water conservancy climate; and structure efficiency need of financial support for agriculture expenditures as input indicators, including support for the cost of farm production expenses and various agricultural 
undertakings, rural development expenditures, and breeding, agricultural machinery, agricultural and food subsidies. Spending property subject generally selects the representative agricultural production development of agriculture, forestry, animal husbandry and fishery as the gross output value index. DEA model is as follows:

$$
\begin{gathered}
\min _{\theta . \lambda}\left[\theta-\varepsilon e^{t} s^{-}+e^{t} s^{+}\right. \\
\text {S.t. }\left\{\begin{array}{l}
\sum_{i=1}^{n} \lambda i y i-s^{+}=y_{0} ; \sum_{i=1}^{n} \lambda_{i} \chi_{i}+s^{-}=\theta x_{0} \\
\sum_{i=1}^{n} \lambda_{i}=1 ; \lambda_{i} \geq 0 ; s^{+} \geq 0 ; s^{-} \geq 0
\end{array}\right.
\end{gathered}
$$

In the model, $\mathrm{n}$ denotes the number of the decision making units, efficiency of decision making units value, said weight coefficient. And $\mathrm{Xi}$, Yi said the decision unit of input and output value and $\mathrm{S}+$ input or output index of relaxation degree. If $=1, \mathrm{~s}-=0, \mathrm{~s}+=0$, is that the decision making units to achieve the DEA effective condition; if $=1$, but $\mathrm{s}=0$ and $\mathrm{S}+=0$, is that the decision making unit is weak DEA efficient; on the contrary, DEA is invalid.

In general, the operation efficiency of the funds of financial agriculture, mainly by the technical efficiency, total factor productivity, scale efficiency of three kinds of efficiency value to be assessed to determine ${ }^{[1]}$. Among them, the ratio of technical efficiency and pure technical efficiency equals to economies of scale; the ratio of technical efficiency and total factor productivity equals to the progress of science and technology; the product of pure technical efficiency, scale efficiency, the progress of science equals to total factor productivity.

\section{Evaluation on the efficiency of financial support for agriculture in China}

\subsection{Basic trends}

Relevant statistics, in 2004, the efficiency of fiscal support for agriculture in China, reached the peak at 1.009,2007 and reached 0.859 at trough. From 2000 to 2007, the period from the National Financial Fund for Agriculture efficiency was in downward trend, indicating that the utilization of financial resources did not increase with the rise of national investment ${ }^{[2]}$. From the table we can see that although during the last eight years, our country finance for supporting agriculture fund increased year by year, but the funds utilization rate has not risen, on the one hand illustrates the China fiscal agricultural supporting policy system, investment structure is not reasonable. Its capital using efficiency index change as table 1 :

Table 1: the change of China's fiscal expenditure for agriculture use efficiency index :

\begin{tabular}{cccccc}
\hline index & Technical efficiency & $\begin{array}{c}\text { Pure technical } \\
\text { efficiency }\end{array}$ & $\begin{array}{c}\text { Scientific and } \\
\text { technological }\end{array}$ & Scale benefit & $\begin{array}{c}\text { Total factor } \\
\text { productivity }\end{array}$ \\
\hline 2001 & 0.609 & 0.805 & 1.606 & 0.756 & 0.978 \\
\hline 2002 & 1.587 & 1.207 & 0.566 & 1.315 & 0.898 \\
\hline 2003 & 1.026 & 1.067 & 0.948 & 0.962 & 0.973 \\
\hline 2005 & 0.893 & 0.83 & 1.131 & 1.067 & 1.009 \\
\hline 2006 & 1.075 & 1.126 & 0.885 & 0.955 & 0.952 \\
\hline 2007 & 1.010 & 1.024 & 0.92 & 0.987 & 0.93 \\
\hline average & 0.963 & 0.87 & 0.892 & 1.105 & 0.859 \\
\hline
\end{tabular}




\subsection{Financial support and agricultural development}

Modern agriculture has attached greater importance to agricultural products output quality and agricultural science and technology innovation, resource conservation. China's financial support is required for agricultural development expenditures for fiscal expenditure for agriculture. From the point of view of academia and the practice departments, the fiscal expenditure for agriculture statistical points for the broad and narrow sense. The narrow fiscal agricultural expenditure includes fund spending on agricultural production, agriculture, forestry, water conservancy, meteorological service expenditure, expenditure for comprehensive development of agriculture, agricultural infrastructure expenditure, agricultural science and technology expenses; and general fiscal agricultural expenditure is mainly refers to the narrow branch of a coupled with fiscal funds, and through other indirect ways for agriculture to support and subsidies.

\subsection{Evaluation and efficiency of financial expenditure on Agriculture}

Efficiency of fiscal expenditure for agriculture is mainly refers to the comparisons between the government agricultural development finance input and agricultural output efficiency, its implicit fiscal agricultural expenditure of funds of the run configuration is efficient and scientific rationality, its efficiency is generally divided into structural efficiency, scale efficiency and effects of rate of the three major categories.

In general, fiscal agriculture expenditure efficiency evaluation mainly conducted in two ways. One is through the establishment of production function, estimating elasticity of output to expenditure efficiency evaluation. Usually, expenditure elasticity coefficient is bigger, efficiency is higher. Evaluation with regression coefficients of quasi method for measurement and calculation of output elasticity, income regression coefficients to represent the expenditure elasticity. Output elasticity evaluation mechanism is mainly used for the efficiency evaluation of the expenditure structure.

Second relative efficiency evaluation method. This method is by calculating the relative efficiency of the different units of the same nature to carry on the comparison and analysis. The method can be used to measure a variety of agricultural expenditure efficiency, including structural efficiency, scale efficiency, usage efficiency. In recent years, DEA model, use more, this way of data requirements relatively low to multi output on the subject of investment and investment efficiency evaluation. Evaluation of fiscal agriculture expenditure efficiency indicators used can be divided into two categories, namely input indicators, output indicators. The input index is to support agricultural development of financial expenditure structure, expenditure scale; output indicators for agricultural Gross industrial output value, planting area, per capita income of farmers

\subsection{Evaluation of the efficiency of domestic financial expenditure on Agriculture}

Since the 1980s, Lucas, Romer representative economists, based on the new classical economic growth, began to work on national economic sustained growth by economic system endogenous variables influence, this is the endogenous economic growth theory. The endogenous economic growth theory to the population growth rate, savings rate, 
technological progress see as affecting economic growth variable. In raw economic growth model is assumed constant marginal returns to capital, the capital project includes the development of human capital, material capital, knowledge accumulation for parents of a country's economic growth intrinsic motivation, these variables with general has a strong externality, public product characteristics.

\section{Research conclusions and policy recommendations}

\subsection{Conclusions of the study}

Domestic agricultural development goal is to realize the construction of agricultural modernization, but to achieve the construction of agricultural modernization, need the government's financial support. In recent years, the domestic economy is relatively slow growth, fiscal revenue growth also than weak. In addition, financial operation is about to enter the period of contraction, if only to rely on fiscal agricultural expenditure, for rural economic development is extremely unfavorable, which requires from the improvement of the efficiency in the use of funds to begin. Through the practice certificates, the efficiency of our domestic financial support for agriculture is not optimistic, regardless of is from the development situation of the various provinces, or from the point of view of the regional average, widespread loss of efficiency, the loss of the situation, especially the pure technology efficiency loss is more serious

\subsection{Policy recommendations}

4.2.1 Increase financial support agriculture investment, the reasonable control of agriculture funds. First of all, the domestic financial sector should continue to increase the input of funds for supporting agriculture, and the establishment of agricultural investment legal norms to ensure fiscal investment growth speed and scale. In the second place, the need for domestic regional financial investment is not balanced, the transfer payment system to improve and in the area between the rational allocation of fiscal agricultural expenditure of funds, as far as possible to improve the overall fiscal agriculture fund size and efficiency. Especially in the western region, need to increase the support of financial support for agriculture, of agriculture related funds supporting mechanism reform, the decrease of developed areas supporting pressure [3].

4.2.2 Optimization and upgrading of the fiscal agriculture expenditure structure, effectively enhance the structure efficiency in the use of funds. In domestic financial funds for agriculture expenditure, agricultural machinery, food, crops and agricultural subsidies expenditure efficiency is relatively high, and it is in an increasing stage of returns to scale, so it should increase the expenditure proportion, the more agricultural projects belong to the scope of financial subsidies. In addition, but also to build accurate input mechanism, increase subsidies to accuracy, guarantee funds effectively issued, in order to improve the efficiency of the funds of financial agriculture input. And to rural social development expenditure and support agricultural production expenditure and the Industry fees and need to reduce non-productive expenditure, increase the productive expenditure and increase rural basic public service investment and agricultural infrastructure construction, reduce administrative expenses, increase the promotion and innovation of science and technology expenditure, so as to optimize the funds of financial agriculture expenditure structure. 
4.2.3 To improve our country finance supporting agriculture fund supervision mechanism and our country's fiscal agriculture fund use efficiency, we need to strengthen the supervision and control of funds from various aspects: effectively improve the structure of capital allocation and use efficiency combined with the new budget law, perfect our country agriculture finance pre calculate regulatory mechanisms, formed beforehand, conduct supervision, improve supervision efficiency of the financial funds for agriculture. In addition, it is necessary to improve the fiscal funds of the integration mechanism to effectively reduce the waste of money.

\section{Conclusion}

Altogether, the development of agricultural production, is inseparable from the support of national finance. In order to improve the financial supporting agriculture funds use efficiency, it is necessary to make analysis and evaluation on the various factors, through the adjustment of the policy and regulatory capital whereabouts, effectively improve the utilization efficiency of the financial funds for agriculture and promoting modern agriculture will continue to grow.

\section{References}

[1] Li Guilan Wang Dan. Performance evaluation of financial support for agriculture in county level based on, DEA entrepreneur world, vol.9, pp.95-97, 2013.

[2] Huang Qinghua, Wei Xiaoya. Performance evaluation of financial support for agriculture in Guizhou Province Based on DEA two response model, Journal of agricultural machinery, vol.34:01, pp.241-244, 2013.

[3] Jiang Song, Cao Zhenglin. Coordination efficiency and evolution of financial support for agriculture in China, soft science, vol.02:27, pp.6-11, 2013.

[4] Wang Dingxiang, Ju Lijuan. Measure the efficiency of finance support for agriculture of our country and improvement strategies, Contemporary economic research, vol.11, pp.62-69, 2013.

[5] Wang Xiao, Zhang Qin. The efficiency of financial support for agriculture in Zitong County of Mianyang city based on DEA model, Times finance, vol.05:15, pp.230-231, 2014. 